\title{
LEYES GENERALES EN MÉXICO ${ }^{1}$
}

\author{
Odracir Ricardo Espinoza Valdez
}

\begin{abstract}
"Recordemos que lo que buscamos (creo) es justicia para las víctimas y debido proceso para los presuntos culpables. Sólo así la justicia será digna de su nombre"2, José Woldenberg, 17 de junio de 2010.
\end{abstract}

\section{Resumen}

El incansable anhelo del profesional del derecho en la búsqueda de la justicia, hoy cuenta con herramientas de interpretación que van orientadas a fortalecer y dar certeza a los ciudadanos, seguridad jurídica no solo nacional, también internacional, dándole un valor rector a las LEYES GENERALES, es por lo que presentamos en este trabajo, en primer lugar una de las mejores interpretaciones al Artículo 133 Constitucional a cargo del Dr. Carpizo, quien destaca con claridad lo que consideramos fundamental, la "SUPREMACÍA CONSTITUCIONAL" y sus impactos en el desarrollo de la Sociedad Mexicana.

Posteriormente hacemos una distinción clara y conceptual, definiendo lo que son las Leyes Federales y las leyes Generales, destacando lo vinculante internacionalmente hablando de las Generales, derivado de las últimas reformas constitucionales, presentando una jerarquización interesante, para finalmente acercarnos a una conclusión lo más apegada y coherente con la realidad jurídica que vivimos actualmente; Donde se violan los derechos humanos, es posible que el antecedente sean actos de corrupción, que atentan contra las normas Generales, luego entonces tenemos hoy, más instrumentos no solo nacionales, también internacionales para perseguir y sancionar a quien presuntamente comete actos de corrupción que como consecuencia violen derechos humanos, agregamos este tópico para ver los alcances de las Leyes generales en ese tema.

\section{Introducción.}

La Constitución Política de los Estados Mexicanos en su artículo 133, establece que: "Esta Constitución, las leyes del Congreso de la Unión que emanen de ella y todos los tratados que estén de acuerdo con la misma, celebrados y que se

${ }^{1}$ Ensayo realizado para la asignatura Adecuación del Estado y la Administración Pública en México del Programa de Doctorado en Administración Pública, ISAPAC 2 José Woldenberg, MÉXICO: LA DIFICIL DEMOCRACIA, en el análisis que hace el autor sobre diferentes temas, uno central es precisamente el actuar de las oficinas de procuración de justicia, así como los criterios de la SCJN. 
celebren por el Presidente de la República, con aprobación del Senado, serán la Ley Suprema de toda la Unión. Los jueces de cada entidad federativa se arreglarán a dicha Constitución, leyes y tratados, a pesar de las disposiciones en contrario que pueda haber en las Constituciones o leyes de las entidades federativas".

Señala el Dr. Jorge Carpizo, que es precisamente la Constitución el alma y la salvia que nutre y vivifica el derecho base de las instituciones e ideario de un pueblo. ${ }^{3} \mathrm{Y}$ continua destacando el término "SUPREMACÍA CONSTITUCIONAL", el cual como el maestro Carpizo indica se refiere precisamente a la seguridad que obtenemos los hombres por la unidad que se otorga al sistema de normas ya que no es posible que exista una norma contraria ya sea como lo indica el maestro de forma material o formal, a esta NORMA SUPERIOR, lo que para muchos se ha catalogado con la Jerarquía Constitucional de la norma.

\section{Desarrollo}

El tema de las "LEYES GENERALES EN MÉXICO" contiene diversos elementos importantes en el ámbito jurídico, para ello, tenemos que partir de conceptos normativos diferentes para no confundir el espíritu del constituyente.

Las LEYES FEDERALES, son aquellas que regulan las atribuciones conferidas a determinados órganos, con el objeto de trascender ÚNICAMENTE, (y lo pongo en mayúsculas porque es fundamental destacar esto) al ámbito federal, son leyes orgánicas principalmente, lo que para diversos autores son mayormente de contenido de "forma", no de "fondo" o de contenido normativo.

Dejando me parece claro que el ámbito internacional, esta reservado para las LEYES GENERALES ${ }^{4}$.

LEYES GENERALES, son aquellas que pueden incidir válidamente en todos los órdenes jurídicos parciales que integran al Estado Mexicano. Es decir, como lo

3 Jorge Carpizo, en su interpretación al artículo 133 Constitucional, en artículo publicado por el Instituto de Investigaciones Jurídicas de la UNAM.

${ }^{4}$ Las cursivas son propias. 
explica la Tesis: P. VII/2007, las leyes GENERALES corresponden a aquellas respecto a las cuales el Constituyente o el Poder Revisor de la Constitución ha renunciado expresamente a su potestad distribuidora de atribuciones entre las entidades políticas que integran el Estado Mexicano. Es, considero fundamental subrayar lo que esta tesis de la Corte señala, cuando habla del origen de estas normas, que están en cláusulas constitucionales que obligan al Congreso de la Unión, a dictarlas y estas deberán ser aplicadas por todas las autoridades, tanto federales, locales, como municipales, hablamos entonces del principio de SUPREMACÍA, así mismo, podemos percibirlo como la extensión de derechos facultando al Estado con parámetros mínimos para su cumplimiento, cabe señalar que hay excepciones, particularmente en algunas normativas históricas como el caso de la Ley Federal del Trabajo que no es una Ley General del Trabajo, pero es Federal y norma tanto la forma, como el fondo en materia de los derechos y obligaciones en materia laboral.

En relación a los tratados internacionales en la medida que el Estado mexicano los suscribe, de conformidad con lo dispuesto en la Convención de Viena y atendiendo al principio "pacta sunt servanda" este (el Estado mexicano), contrae libremente obligaciones frente a la comunidad internacional y QUE NO PUEDEN SER DESCONOCIDAS, invocando normas de derecho interno, además su no cumplimiento supone una responsabilidad internacional, la Tesis: P. IX/2007 en relación a lo anterior concluye: "los tratados internacionales se ubican jerárquicamente debajo de la Constitución Federal y por encima de las les generales, federales y locales..."

Se abre entonces en el mundo del derecho internacional, un gran número de acciones vinculantes que en particular tienen que ver con la violación de derechos humanos, donde se pueden solicitar sanciones a Estados que no cumplan con los tratados firmados, sanciones que tienen que ver directamente en muchos casos con acceso a fondos internacionales del Banco Mundial, del Fondo Interamericano, o están sujetos a calificaciones negativas en indicadores internacionales que determina la OCDE, si establecemos una relación del derecho 
internacional con el avance que en nuestro país se ha tenido en normar dicho derecho, se ha realizado de forma puntual precisamente en las leyes generales, por ser de contenido principalmente programáticas.

Algunos ejemplos de LEYES GENERALES, son: la Ley General de Salud, la Ley General de Asentamientos Humanos, la Ley General de Cultura Física y Deporte, la Ley General de Educación, la Ley General de Equilibrio Ecológico y la Protección al Ambiente, la Ley General de Transparencia, etc. Si observamos con cuidado las leyes generales que existen, nos damos cuenta que estas leyes son "distribuidoras" como las llama Oscar Gutiérrez Parada ${ }^{5}$, de facultades y donde no hay duda que son LEYES GENERALES, distinguimos un interés evidente de agendas internacionales, ya que son en temas como la educación y salud, derechos inclusive colectivos o de tercera generación, donde al no regularse y al no poder ser constitucionalmente su regulación por no ser materia de la misma, existen estas leyes generales y su vez su existencia, sirve para evitar propiciar graves violaciones a derechos humanos al no contar con normatividad secundaria los derechos humanos para su operatividad, se busca entonces, proteger intereses colectivos que nos vinculan con los intereses de la comunidad democrática internacional, hablamos de derechos sociales, por lo que son base de construcción normativa nacional y rostro de un país al exterior, su validez no se cuestiona en todo el territorio nacional.

\section{Conclusiones}

Retomando el punto del Dr. Jorge Carpizo, cuando señala la "cierta seguridad" que los hombres, que los ciudadanos podemos tener o sentir en todo el territorio nacional ya que la SUPREMACÍA, que la cual están dotadas las LEYES GENERALES, da unidad al sistema normativo nacional.

\footnotetext{
${ }^{5}$ Ponencia presentada por Oscar Gutiérrez Parada, presentada en el CONGRESO REDIPAL (VIRTUAL V. Enero-agosto 2012), CÁMARA DE DIPUTADOS. Donde partiendo de las reformas Constitucionales del 2011 en materia de derechos humanos desarrolla su ponencia.
} 
Partiendo del principio anterior y como antecedente próximo la nueva estructura jerárquica que a partir del 7 de junio del 2011, donde se publicaron las modificaciones del decreto publicado en el Diario Oficial de la Federación y el artículo $1^{\circ}$ Constitucional quedó como sigue: "En los Estados Unidos Mexicanos todas las personas gozarán de los derechos humanos reconocidos en esta Constitución y en los tratados internacionales de los que el Estado Mexicano sea parte, así como de las garantías para su protección, cuyo ejercicio no podrá restringirse ni suspenderse, salvo en los casos y bajo las condiciones que esta Constitución establece." Entonces podemos señalar una nueva estructura jerárquica:

- Constitución y Tatados internacionales de Derechos Humanos;

- Leyes Generales

- Leyes Federales; Leyes Estatales;Leyes Municipales

- Disposiciones reglamentarias;

- Disposiciones administrativas.

Finalmente hoy es importante que donde se violan derechos humanos, es posible que se estén cometiendo actos de corrupción por falta de normatividad aplicable, esquemas de discrecionalidad, es necesario señalar (pero no lo fue hasta hace realmente poco), que si un funcionario desvía recursos, por ejemplo recursos provenientes del sistema de salud, se están violando derechos humanos fundamentales de acceso a la salud, luego entonces los tratados firmados por el Estado mexicano en esta materia son vinculantes para sancionar al funcionario si es que la justicia nacional no tuvo elementos suficientes, incluso puede recomendar sanciones económicas contra un país limitando al acceso de recursos y mejores condiciones de desarrollo democrático, es entonces altamente relevante dejar claro que la SUPREMACÍA es la garantía que puede fortalecer la confianza de los ciudadanos en las instituciones, pero ¿qué pasaría si no contamos con una ley que señale como deben cumplirse esos mandatos del derecho a la Salud? ¿Si no existe una ley general que establezca los alcances y formas de cumplimiento de dicho derecho, queda a la discrecionalidad del servidor público?, si, en gran medida, por ello de la relación señalada y la importancia de las Leyes generales. 
Bobbio señala "Teóricamente, debería prevalecer el criterio jerárquico ya que, si se admitiese el principio de que una ley ordinaria especial puede derogar los principios constitucionales, que son normas generalísimas, los principios fundamentales de un ordenamiento jurídico estarían condenados a perder todo contenido..." sin embargo también Bobbio advierte sobre las circunstancias de tiempo y realidad que la sociedad esta viviendo. Hoy la agenda apunta hacia la protección de derechos humanos, pero no únicamente en la norma fundante o en los tratados internacionales, sino también en las leyes generales que establecen los contenidos y alcances de los derechos humanos, cumpliendo con ello con la responsabilidad del Estado de hacer cumplir dichos derechos de la sociedad.

\section{Bibliografía y Webgrafía}

Bobbio, Norberto, Teoría General del Derecho, Debate, Madrid, España, 1991.

Constitución Política de los Estados Unidos Mexicanos, 2017.

Gutiérrez Parada Oscar, "Qué caracterizamos bajo la locución "leyes generales": tratados internacionales de derechos humanos y estructura jerárquica del sistema jurídico mexicano", Ponencia presentada en: CONGRESO REDIPAL, 2012, CÁMARA DE DIPUTADOS.

LA INTERPRETACIÓN DEL ARTÍCULO 133 CONSTITUCIONAL, por Jorge Carpizo comparado/article/view/605/865.

LEYES GENERALES. INTERPRETACIÓN DEL ARTÍCULO 133 CONSTITUCIONAL, Novena Época, Registro: 172739, Instancia: Pleno, Tesis Aislada, Fuente: Semanario Judicial de la Federación y su Gaceta XXV, abril de 2007, Materia(s): Constitucional, Tesis: P. VII/2007, Páginas: 5.

TRATADOS INTERNACIONALES. SON PARTE INTEGRANTE DE LA LEY SUPREMA DE LA UNIÓN Y SE UBICAN JERÁRQUICAMENTE POR ENCIMA DE LAS LEYES GENERALES, FEDERALES Y LOCALES. INTERPRESTACIÓN DEL ARTÍCULO 133 CONSTITUCIONAL, Novena Época, Registro: 172650, Instancia: Pleno, Tesis Aislada, Fuente: Semanario Judicial de la Federación y su Gaceta XXV, Abril de 2007, Materia(s): Constitucional, Tesis: P. IX/2007, Página: 6. 